\title{
Neurodevelopmental Outcome of High Risk Babies at One Year of Age Born in a Tertiary Centre
}

\author{
Shrestha $M^{1}$, Bajracharya $L^{2}$, Shrestha $L^{3}$
}

\begin{abstract}
Introduction: With increasing survival of high risk babies, children with different developmental disabilities have emerged as a challenge for the baby, family as well as for physicians. With limited awareness and resources, follow-up and interventions for these babies are difficult. The study was carried out to find out the development of high risk babies in different developmental domains at one year of age. Material and Methods: NICU graduates who visited high risk clinic at one year of age were assessed. ASQ-3 was used to screen development. Children with major congenital anomalies and syndromes were excluded from the study. Results: Out of 28 high risk babies, about $29 \%$ had global delay. Those babies who had seizure during neonatal period could not score even in single item of ASQ-3. Conclusion: All high risk babies are at risk of developing delay hence should be followed up regularly. Timely early intervention needs to be started to minimize delay.

Key words: Developmental delay, High-risk, One year
\end{abstract}

\section{Introduction}

B abies who are born preterm, asphyxiated, had severe infections in early period of life and required prolonged intensive care during neonatal period are always at risk of developing different developmental disabilities. Improved survival of these babies in contrary has emerged with more challenges in later life ${ }^{1}$.

Tribhuvan University Teaching Hospital is a referral center for obstetric and neonatal care and patients from all over the country are referred here. About $10 \%$ of the babies born here get admitted in nursery and of them $7 \%$ had birth asphyxia ${ }^{2}$. Survivors of birth asphyxia are at risk for neurodevelopmental sequelae including motor and cognitive disabilities ${ }^{3,4,5,6,7}$. Zambian study has shown that there is four times more chance of having abnormal neurologic outcome in infants who have asphyxia at birth ${ }^{8}$. Similar study in Kathmandu has also shown that newborns who were asphyxiated and had encephalopathy at birth, $28 \%$ developed cerebral palsy ${ }^{9}$. Prematurity is another important risk for developing developmental disabilities. In recent years there is $70 \%$ increase in preterm delivery in $\mathrm{TUTH}^{10}$. With improved care of these babies, the survival of severe, moderate and late preterm babies is $80 \%, 78$ and $95 \%$ respectively ${ }^{11}$. For these babies, timely developmental assessment carries an immense role in identifying any delay and initiating for early multi-disciplinary
${ }^{1}$ Dr. Merina Shrestha, MBBS, MD, Assistant Professor, ${ }^{2}$ Dr. Luna Bajracharya, MBBS, MD, Assistant Professor, ${ }^{3} \mathrm{Dr}$. Laxman Shrestha, MBBS. MD, Professor. All from Department of Child Health, Tribhuvan University Teaching Hospital, Kathmandu, Nepal.

\section{Address for correspondence \\ Dr. Merina Shrestha, Assistant Professor Department of Child Health, Institute of Medicine \\ Tribhuvan University Teaching Hospital Maharajgunj, Kathmandu, Nepal \\ Tel No: +977-1-4412202 \\ E-mail: drmerinashrestha@gmail.com}

Acknowledgements: We would like to thank all the staffs of NICU who counseled parents for the follow up in high-risk clinic at schedules time. We would also like to thank staffs from high-risk clinic who helped during assessment. We are very grateful towards all parents who made sure to visit us at scheduled date for assessment

Funding: Nil

Conflict of Interest: None

Permission from IRB: Yes

\section{How to cite}

Shrestha M, Bajracharya L, Shrestha L. Neurodevelopmental Outcome of High Risk Babies at One Year of Age Born in a Tertiary Centre. J Nepal Paediatr Soc 2017;37(1):4550.

doi: http://dx.doi.org/10.3126/jnps.v37i1.16242

This work is licensed under a Creative Commons Attribution 3.0 License.

\section{(c) (P)}


interventions. Developmental outcome is found to be significantly better when early intervention is initiated to preterm low birth weight babies ${ }^{12}$.

Thus the current study was carried out with an objective to find out the neurodevelopment outcome of high risk babies born at TUTH.

\section{Material and Methods}

Study setting and population: As per hospital protocol, Neonatal Intensive Care Unit (NICU) and nursery graduates are advised to visit high-risk clinic. High risk clinic is run twice a week by two faculties and two residents at a time. First follow up visit is done at 2 weeks after discharge. Other visits are scheduled to coincide with the vaccination schedule at 6,10 and 14 weeks and 9, 12 and 15 months of age. Parents are also advised to visit at 6 months and whenever they have any concern. During follow up visits, growth and developmental assessments, screening for retinopathy of prematurity or other visual problems, audiological assessments are performed and investigations including neuroimaging and electroencephalography are done when indicated. During each visit, parents are counseled regarding different interventions including physiotherapy. Parents are taught about visual, tactile, auditory stimulations that can be performed at home.

The current study was conducted between, August 2014 till February 2017. Inborn high-risk babies who visited the clinic at 12 months and whose parents gave consent were enrolled. Babies who had syndromic diagnosis or major congenital anomalies were not included. For preterm babies, corrected age was considered for developmental assessment. Neonatal data was retrieved from hospital records. Other demographic data were collected from parents' interview. Detail neurological examination and developmental assessment was performed in a quiet and separate room.

Development assessment: For developmental assessment of a child, Bayley Scales of Infant Development (BSID) is considered as the gold standard. However, BSID assessment tool is expensive and requires lot of time and skilled manpower/psychologist who is trained on performing this test. Thus in developing country like ours with limited resources instead of BSID, assessing children with Age and Stages Questionnaire-3 (ASQ-3) is promising. ASQ has adequate psychometric properties with sensitivity of $75 \%$ and specificity of $81 \%$ and can be used for screening for both low risk and risk babies ${ }^{13}$. When used in Indian setting, ASQ was found to have sensitivity of $92.3 \%$ in high-risk babies ${ }^{14}$.

ASQ-3 is a questionnaire based comprehensive developmental screening tool which addresses five developmental domains namely: Communication, Gross Motor, Fine Motor, Problem Solving and Personal Social. For each domain there are six questions, thus altogether there are 30 questions in different age groups. The whole questionnaire is divided in 21 different age groups: 2,4,6,8,9,10,12,14,16,18,20,22,24,27,30,33,36, $42,48,54$ and 60 months. For the current study we used 12 months questionnaire.

Few of the questions are repeated whereas few questions are age specific. The questions are simple and the expected answer for each question is "Yes", "Sometimes" or "No" and the scores are 10, 5 and 0 respectively.

Parents/Caregivers who have grade $\mathrm{V}$ and above education level can easily fill these forms. However, in the current study "Home procedure" was followed. In this procedure, the performed items can be directly observed by the examiner. In items where children do not perform, questions are asked to parents whether they perform these items at home or not. Tools and toys required for the assessment was made available locally. Translation and back translation of the questionnaire was done following the official recommendations for standards in the translational and adaptation process ${ }^{15}$. For each assessment it takes about 15-20 minutes.

Statistical analysis was performed with SPSS 20.

Ethical approval was taken from Institutional Review Board of loM-TUTH.

\section{Results}

Total of 28 babies were enrolled. The mean (SD) age of mother and father was 29 (3.9) and 33.6 (3.8) years, respectively. All parents were literate and more than half of them had graduate level education. Sixty eight percent of mothers were housewives. All the babies were residing in Kathmandu.

Of total babies, half of them were term. Fifty percent of the babies were low birth weight. Male babies (61\%) outnumbered female babies (39\%). About half of them were born via low section cesarean section and $18 \%$ required active neonatal resuscitation at birth. The mean duration of NICU stay was 10.2 (7.9) days. Mechanical ventilation was required for $8(28.6 \%)$ babies with mean duration of 3.5 (1.2) days.

Twenty four babies were brought for all scheduled visits and $60 \%$ of the parents were concerned about the development of the child. At one year of age, 20 children were found to be developmentally normal, 7 had global delay and one had spastic cerebral palsy. Profile of children who were delayed at one year of age is described in Table 2. 
Table1: Demographic characteristics of the participants $(n=28)$

\begin{tabular}{lc}
\hline \multicolumn{1}{c}{ Characteristics } & Total Number (n=28) \\
\hline Gestational Age at birth & - \\
\hline $31-33$ weeks & 5 \\
\hline $34-36$ weeks & 14 \\
\hline 37 weeks and above & - \\
\hline Birth weight & 14 \\
\hline 1400 -2500 grams & 14 \\
\hline Above 2500 grams & 17 \\
\hline Antenatal problem & 5 \\
\hline Pregnancy induced hypertension & 5 \\
\hline Prolong rupture of membrane & 4 \\
\hline Fetal distress with meconium & 1 \\
\hline Oligohydroamnious & 1 \\
\hline Maternal Hypothyroidism & 1 \\
\hline Maternal Cardiomyopathy & - \\
\hline Neonatal Morbidities & 8 \\
\hline Sepsis/pneumonia/meningitis & 3 \\
\hline Hypoxic Ischemic Encephalopathy & 7 \\
\hline Respiratory Distress of Prematurity & 1 \\
\hline Meconium Aspiration Syndrome with pneumothorax & 1 \\
\hline Low Birth Weight for supportive care & 2 \\
\hline Pathological Jaundice requiring exchange transfusion & 1 \\
\hline Neonatal Seizure & \\
\hline
\end{tabular}

Table 2: Means, standard deviation and range of the total ASQ-scale score and the five subscale scores for developmentally normal children $(\mathrm{N}=20)$

\begin{tabular}{ccccccc}
\hline & Total Scale & Communication & Gross motor & Fine motor & $\begin{array}{c}\text { Problem } \\
\text { solving }\end{array}$ & Personal social \\
\hline Mean & $232(30)$ & $53.5(7.9)$ & $41.7(14.6)$ & $49.5(6.8)$ & $46(8.8)$ & $43(12.7)$ \\
\hline Range & $0-300$ & $0-60$ & $0-60$ & $0-60$ & $0-60$ & $0-60$ \\
\hline Cut off & - & 15.64 & 21.49 & 34.50 & 27.32 & 21.73 \\
\hline
\end{tabular}

Table 3: Profile of children who have developmental delay at one year of age

\begin{tabular}{cccccccc}
\hline ID & GA & BW & $\begin{array}{c}\text { Intervention in } \\
\text { NICU }\end{array}$ & $\begin{array}{c}\text { NICU stay } \\
\text { (in days) }\end{array}$ & Neonatal Diagnosis & Neuroimaging & $\begin{array}{c}\text { Total ASQ } \\
\text { Score }\end{array}$ \\
\hline 1 & 33 & 1400 & Surfactant/ MV & 28 & RDS of prematurity/sepsis & NA & 45 \\
\hline 2 & 34 & 2000 & Oxygen & 21 & Neonatal Seizure & ${ }^{*}$ Normal & 0 \\
\hline 3 & 34 & 2100 & Oxygen & 7 & $\begin{array}{c}\text { Hypoxic Ischemic } \\
\text { Encephalopathy }\end{array}$ & *Encephalomalacia with \\
chronic EDH & 0 \\
\hline 4 & 35 & 2700 & Surfactant / MV & 30 & RDS of Prematurity & ${ }^{*}$ Frontal lobe atrophy & 135 \\
\hline 5 & 37 & 2600 & Oxygen & 4 & Neonatal Seizure & ${ }^{*}$ Encephalomalacia & 0 \\
\hline 6 & 37 & 2900 & Oxygen & 5 & Sepsis/Seizure & ${ }^{*}$ Normal & 0 \\
\hline 7 & 38 & 3500 & $\begin{array}{c}\text { Exchange } \\
\text { Transfusion }\end{array}$ & 5 & Pathological Jaundice & NA & 30 \\
\hline 8 & 39 & 3000 & MV & 18 & $\begin{array}{c}\text { Sepsis/refractory } \\
\text { hypoglycemia/seizure }\end{array}$ & $\begin{array}{c}\text { \#Diffuse hypodensity in } \\
\text { bilateral cerebral hemisphere }\end{array}$ & 130 \\
\hline
\end{tabular}

ID: Identification; GA: Gestational age in weeks; BW: Birth weight in grams ; MV; Mechanical Ventilation; RDS: Respiratory Distress Syndrome; EDH: Extradural Hemorrhage Neuroimaging: \# Computed Tomography; * Magnetic Resonance Imaging; NA: not done 
Table 4: Total ASQ-scale score and the five subscale scores for developmentally delayed children

\begin{tabular}{|c|c|c|c|c|c|c|}
\hline ID & Total Score & Communication & Gross motor & Fine motor & Problem solving & Personal social \\
\hline 1 & 45 & 20 & 5 & 5 & 5 & 10 \\
\hline 2 & 0 & 0 & 0 & 0 & 0 & 0 \\
\hline 3 & 0 & 0 & 0 & 0 & 0 & 0 \\
\hline 4 & 135 & 15 & 25 & 30 & 30 & 35 \\
\hline 5 & 0 & 0 & 0 & 0 & 0 & 0 \\
\hline 6 & 0 & 0 & 0 & 0 & 0 & 0 \\
\hline 7 & 30 & 15 & 0 & 5 & 10 & 0 \\
\hline 8 & 130 & 15 & 15 & 50 & 25 & 25 \\
\hline Range & $0-300$ & $0-60$ & $0-60$ & $0-60$ & $0-60$ & $0-60$ \\
\hline Cut off & - & 15.64 & 21.49 & 34.50 & 27.32 & 21.73 \\
\hline
\end{tabular}

ASQ-3: 12 month questionnaire (11 months 0 days through 12 months 30 days) Adapted fro: Ages \& Stages Questionnaires $®$, Third Edition (ASQ3TM), Squires \& Bricker (C) 2009 Paul H. Brookes Publishing Co.

\section{Communication}

1. Does your baby make two similar sounds, such as "ba-ba," "da-da," or "ga-ga"? (The sounds do not need to mean anything.)

2. If you ask your baby to, does he play at least one nursery game even if you don't show him the activity yourself (such as "bye-bye," "Peeka- boo," "clap your hands," "So Big")?

3. Does your baby follow one simple command, such as "Come here," "Give it to me," or "Put it back," without your using gestures?

4. Does your baby say three words, such as "Mama," "Dada," and "Baba"? (A "word" is a sound or sounds your baby says consistently to mean someone or something.)

5. When you ask, "Where is the ball (hat, shoe, etc.)?" does your baby look at the object? (Make sure the object is present. Mark "yes" if she knows one object.)

6. When your baby wants something, does he tell you by pointing to it?

\section{Gross Motor}

1. While holding onto furniture, does your baby bend down and pick up a toy from the floor and then return to a standing position?

2. While holding onto furniture, does your baby lower herself with control (without falling or flopping down)?

3. Does your baby walk beside furniture while holding on with only one hand?
4. If you hold both hands just to balance your baby, does he take several steps without tripping or falling?

5. When you hold one hand just to balance your baby, does she take several steps forward?

6. Does your baby stand up in the middle of the floor by himself and take several steps forward?

\section{Fine Motor}

1. After one or two tries, does your baby pick up a piece of string with his first finger and thumb?

2. Does your baby pick up a crumb or Cheerio with the tips of her thumb and a finger? She may rest her arm or hand on the table while doing it.

3. Does your baby put a small toy down, without dropping it, and then take his hand off the toy?

4. Without resting her arm or hand on the table, does your baby pick up a crumb or Cheerio with the tips of her thumb and a finger?

5. Does your baby throw a small ball with a forward arm motion?

6. Does your baby help turn the pages of a book? (You may lift a page for him to grasp.)

\section{Problem Solving}

1. When holding a small toy in each hand, does your baby clap the toys together (like "Pat-a-cake")?

2. Does your baby poke at or try to get a crumb or Cheerio that is inside a clear bottle (such as a plastic soda-pop bottle or baby bottle)?

3. After watching you hide a small toy under a piece of paper or cloth, does your baby find it? (Be sure the toy is completely hidden.)

4. If you put a small toy into a bowl or box, does your baby copy you by putting in a toy, although she may not let go of it? 
5. Does your baby drop two small toys, one after the other, into a container like a bowl or box? (You may show him how to do it.)

6. After you scribble back and forth on paper with a crayon (or a pencil or pen), does your baby copy you by scribbling?

\section{Personal Social}

1. When you hold out your hand and ask for his toy, does your baby offer it to you even if he doesn't let go of it?

2. When you dress your baby, does she push her arm through a sleeve once her arm is started in the hole of the sleeve?

3. When you hold out your hand and ask for his toy, does your baby let go of it into your hand?

4. When you dress your baby, does she lift her foot for her shoe, sock, or pant leg?

5. Does your baby roll or throw a ball back to you so that you can return it to him?

6. Does your baby play with a doll or stuffed animal by hugging it?

\section{Discussion}

In resource poor settings like ours NICU care is expensive, scarce and it consumes huge amount of human as well as financial resources. With improved care many newborn babies are surviving with $80 \%$ survival of moderate preterm babies ${ }^{11}$ and this study has tried to see the long term outcome of these high-risk babies. In the current study, $71 \%$ of the babies had scores above the cut off in all domains of development and $28.5 \%$ had global development delay at one year of age. A study by Chattopadhyay et al also found that $31.6 \%$ of their NICU graduates had developmental delay and those babies who had seizure during neonatal period, 46.6 $\%$ had delay ${ }^{16}$. In the current study, six babies found to have profound delay on ASQ assessment. Four babies could not perform on even single item and all of them had neonatal seizure. All these delayed babies were on regular follow up and were receiving multidisciplinary interventions.

Prediction of developmental delay can be done as early as three months of age. Godbole et al' found that absence of social smile at three months and absence of pulling to sit position, transfer of objects and voluntary reach at six months age had specificity of $100 \%$ in predicting developmental delay at one year of age ${ }^{17}$. Thus every high-risk babies need to be monitored so that intervention could be started early. Early intervention is continuously providing multidisciplinary services to infants from the time of birth with periodic development assessment including motor, cognitive and language functioning. Early intervention when started early minimizes delay, prevents functional deterioration and promotes parent child interactions ${ }^{18}$. Parents of high-risk babies can be provided with simple information at the time of discharge from hospital regarding child development and stimulations they can provide at home. At each visit, parents should be reinforced to continue the intervention for their children's optimal development.

Due to small number of children and all children being from Kathmandu, the study is not able to find out how many of NICU graduates actually developed delay. In the study developmentally normal high-risk children were not compared with children without risk and cut off ASQ score for Nepalese children is not available, thus the score should be interpreted with care.

\section{Conclusion}

All the high-risk babies should be monitored with more frequent follow up visits. They should receive early intervention therapy in timely fashion to minimize the delay.

\section{References}

1. Fawke J. Neurological outcomes following preterm birth. Semin Fetal Neonatal Med 2007;12 :374-82. DOI: 10.1016/j.siny.2007.06.002.

2. Shrestha M, Shrestha L, Shrestha PS. Profile of asphyxiated babies at Tribhuvan University Teaching Hospital. J Nepal Paediatr Soc.2009 Vol 29, Issue 1, 3-5.

3. Simon NP. Long-term neurodevelopmental outcome of asphyxiated newborns. Resuscitation Fetus Newborn. 1999;26:767-78.

4. Robertson CMT, Finer NN. Long-term follow-up of term neonates with perinatal asphyxia. Clin Perinatol 1993;20:483-99.

5. Robertson CMT, Finer NN, Grace MGA. School performance of survivors of neonatal encephalopathy associated with birth asphyxia at term. J Pediatr 1989;114:753-60.

6. Cioni G, Prechtl HFR, Ferrari F et al. Which better predicts later outcome in fullterm infants: quality of general movements or neurological examination? Early Hum Dev 1997;50:71-85. 
7. Brookhouser PE. Sensorineural hearing loss in children. Pediatr Clin North Am 1996;43(6):1195-1216.

8. DR Halloran, E McClure, H Chakraborty et al. Birth asphyxia survivors in a developing country. $J$ Perinatol 2009;29, 243-249; doi:10.1038/jp.2008.192.

9. Ellis M, Manandhar N, Shrestha PS, Shrestha L et al. Outcome at 1 year of neonatal encephalopathy in Kathmandu, Nepal. Dev Med Child Neurol 1999;41:689-695; doi: 10.1017/S0012162299001413.

10. M Shrestha, L Shrestha, S Basnet, Shrestha et al. Trends in Perinatal Mortality in Tribhuvan University Teaching Hospital: 13 Years Review. J Nep Paediatr Soc 2012;32(2): 150-153.

11. Shrestha L, Shrestha P. Mortality and Morbidity pattern pf preterm babies at Tribhuvan University Teaching Hospital. J Nepal Paediatr Soc 2013;33(3):201-205.

12. N. Meena, V.K. Mohandas, S. Ramesh et al. Impact of Early Physiotherapy Intervention on Neurodevelopment in Preterm Low Birth Weight Infants. J Dental Med Sci 2012;1(2):29-34
13. L Schonhaut, I Armijo, M Schönstedt et al. Validity of the Ages and Stages Questionnaires in Term and Preterm Infants. Pediatrics 2013;131;e1468. doi:10.1542/ peds.2012-3313

14. M Juneja, M Mohanty, R Jain et al. Ages and Stages Questionnaire as a Screening Tool for Developmental Delay in Indian Children. Indian Pediatr 2012:49;457461.

15. WHO. Management of Substance Abuse, Research Tools. Available from http://www.who.int/substance abuse/research_tools/translation/en/

16. N Chattopadhyay, K Mitra. Neurodevelopmental outcome of high risk newborns discharged from special care baby units in a rural district in India. $J$ Pub Health Res 2015;4:318. doi: 10.4081/jphr.2015.318

17. K Godbole, S Barve and S Chaudhari. Early predictors of neurodevelopmental outcome in highrisk infants. Indian Pediatr 1997;34:491-95. 